\title{
Fetal Outcome Following Umbilical Cord Prolapse in Ahmadu Bello University Teaching Hospital, Kaduna (abuthk), Northern Nigeria.
}

\author{
Onwuhafua P. I. MD Zayyan M. FWACS, MRCOG Ozed-Williams I. FWACS Ankama M. FWACS \\ Division of Maternal and Fetal Medicine, Dept of Obstetrics and Gynecology, ABUTH, Kaduna
}

\begin{abstract}
Background: Umbilical cord is a clinical condition that calls for emergency decision making and action especially with a live and mature fetus. The objective of this study is to determine, fetal outcome and how various factors influence it.
\end{abstract}

Methods: This is a 121/2 year retrospective study of all 34 fetuses who suffered from cord prolapse at Ahmadu Bello University Teaching Hospital.

Results: There were 34 cases of cord prolapse, 23 perinatal deaths and a perinatal mortality rate of $67.64 \%$. About $55 \%$ of babies of registered women died, while about $92 \%$ of the unregistered died. Eleven babies of the 22 women admitted with cervical dilatations of $7 \mathrm{~cm}$ and less, died and all the babies of women with cervical dilatations of $8 \mathrm{~cm}$ and above died.

All 19 babies delivered vaginally and 3 of the 14 delivered abdominally, died.

About eighty eight percent of the low-birth weight, and $37.5 \%$ of normal size babies died.

Seventeen (51.5\%) of the 33 babies delivered, had Apgar score 0.

All babies with Apgar scores 1- 4 died, 40\% with Apgar scores 5-7 and 16.7\% with Apgar scores 8-10 died.

Maternal age, parity, ethnicity, gestational age, presentation and sex of the fetus did not influence outcome.

Keywords: Umbilical cord prolapse, labor, fetal outcome, Kaduna

Paper accepted for publication $13^{\text {th }}$ August 2007.

\section{INTRODUCTION}

The human fetus depends on a bountiful flow of oxygen and nutrients from the placenta for optimum development and ultimate survival. The vital organ through which the oxygen, nutrients to the fetus and also waste products from the fetus must pass is the umbilical cord. This organchannel is normally composed of two umbilical arteries and one umbilical vein in a mesh of connective tissue with abundant nerve endings. It therefore becomes obvious that any mechanical impediment to this two way flow of nutrients and wastes will lead to respiratory and metabolic derangements in the fetus, that, if not relieved will lead to severe degradation of the fetus- infant. An example of this is fetal umbilical cord prolapse.

Four stages of the fetal degradation process during cord prolapse has been described. ${ }^{1}$

The first stage is that of functional hypoxia which is adaptative in nature. This is followed by metabolic hypoxia when the normal anaerobic response to oxygen deprivation fails. This is followed by the stage of morphologic and destructive hypoxia, when irreversible organ lesions occur and finally the stage of anoxia sets in with inevitable organic cerebral lesions. Clinically this is expressed by disorders of fetal heart activities like rhythm, frequency, ECG and phonocardiograph. Biochemically this is translated as a fall in fetal $\mathrm{pH}$.

The clinical consequence of this compression is dependent upon a number of factors, among which are, the intensity of uterine action and presenting fetal part, biologic reserve of the fetus that varies with gestational age and timeliness of intervention.

Medicine and Fetal medicine in particular has benefited immensely from technological advances of recent years, hence the array of equipment that are now available for fetal surveillance in most modern Obstetric units. It is however unfortunate that practice in Nigeria is yet to catch-up with these recent developments.

No study of this condition has ever been done in the hospital and it is believed that the study will help create awareness among practitioners, generate better management practices of this rare condition, stimulate auditing processes and perhaps strengthen the call for a National Maternity Audit Group in Nigeria.

\section{MATERIALS AND METHODS}

This is a retrospective study of all 34 fetuses who suffered from cord prolapse during labor at The Ahmadu Bello University Teaching Hospital, Kaduna (ABUTHK), from January $1^{\text {st }} 1990$ to June $30^{\text {th }}, 2002$.

Birth records of these cases were reviewed for maternal age, parity, ethnic group, booking status, gestational age, duration of cord prolapse, cervical dilatation at presentation, whether or not the cord was outside the vagina, and route of delivery. Feto-infant data included 
status of the fetus at time of diagnosis, fetal presentation, Apgar score at 5 minutes ${ }^{2}$, birth weight, sex of infant and whether or not the infant was referred to the Neonatal Intensive Care Unit.

During the period of study, electronic fetal monitoring and fetal $\mathrm{pH}$ analyses, were not practiced. There was also no existing protocol in the Birth Unit for the management of the condition.

The diagnosis of cord prolapse is accepted if the umbilical cord is palpated below the presenting part on physical examination in the presence of ruptured membranes. Furthermore, a woman is said to be booked for antenatal care, if she had attended the ABUTHK clinic at least once before admission to the labor suite. Also Southern and Northern minority ethnic groups mean here a grouping for the numerous ethnic nationalities in both the North and South of Nigeria that are neither Ibo,Yoruba nor Hausa/Fulani.

Statistical analysis was done using EPI. INFO 6.04 Version - January 2001 Software (C.D.C., USA; WHO Geneva, Switzerland). A probability value of 0.05 is taken as significant.

\section{RESULTS}

During the period there were 34 cases of umbilical cord prolapse among 16633 deliveries.

There were 23 perinatal deaths and a perinatal mortality rate of $67.64 \%$.

The age groups, 20 years and less contributed 2(5.88\%) cases of cord prolapse, 20-34 years $23(67.64 \%)$ and 35 years and above $9(28.47 \%)$.

The para 0 contributed 8 cases of cord prolapse, para1-4, 17 and para 5 and above, 9 cases.

Twenty two of the fetuses' mothers were booked and 12 were not. The mean cervical dilatation of the booked women was $5.96 \mathrm{~cm}(S D=2.19)$, while that of those not booked was $7.75 \mathrm{~cm}(\mathrm{SD}=2.34)$. (F-Statistic=4.94; $p$ value $=0.032630$ )

About $55 \%$ (12) of the 22 babies of booked women died, while about $92 \%$ (11) of the 12 unbooked died. $(p<0.05)$.

There were 9 (26.5\%) fetuses in the less than 34 weeks gestational age group, $10(29.4 \%)$ in the group 34-36 weeks; $15(44.1 \%)$ in the group 37 weeks and above.

Twenty two women were admitted with cervical dilatations of $7 \mathrm{~cm}$ and less, 18 of the fetuses had fetal heart sound on admission; 11(50.0\%) died and these included, 7 fetuses with fetal heart sound; all the 12 women with cervical dilatations of $8 \mathrm{~cm}$ and above lost their babies and these also included 5 with fetal heart sound on admission. $(p<0.05)$
Of the14 fetuses with cephalic presentation, only 4 survived; of the 16 with breech only 6 survived and of the 4 with shoulder presentation only 1 survived. $\left(x^{2}\right.$ $=0.38$, $p$ value $=0.825322$ ) .

There was no significant difference in outcome between fetuses whose umbilical cords were out of the vagina and those not out of the vagina $(x 2=1.65, p$ value $=0.2618743$ )

Nineteen babies were delivered vaginally and none survived while of the14 that had abdominal delivery, only 3 did not survive. $\left(x^{2}=22.4, p\right.$ value $\left.=0.00001372\right)$.

The average weight of babies delivered was $2.52 \mathrm{~kg}$ with a standard deviation of 0.71 ; and with a range of $1.1 \mathrm{~kg}$ being the minimum weight and $3.7 \mathrm{~kg}$ the maximum in the 33 babies.

Seventeen $(51.5 \%)$ of the babies weighed less than $2.5 \mathrm{~kg}$ and 15 of them died and only 2 lived; of the 16 that weighed $2.5 \mathrm{~kg}$ and above only 6 died $(p<0.05)$

Seventeen $(51.5 \%)$ of the 33 babies delivered, had Apgar score 0 (zero), and $8(47.1 \%)$ of these were admitted with live fetuses.

Two babies (6.1\%) had Apgar scores between 1-4 with both babies dead $\left(x^{2}=0.09\right.$, $p$ value $\left.=0.541667\right)$.

Seven babies (21.2\%) had Apgar scores of between 5 and 7 with 5 babies alive and 2 dead $\left(x^{2}=4.87, p\right.$ value $=0.027438$ ).

Seven babies (21.2\%) had Apgar scores of between 8 and 10 with 6 babies alive and 1 dead $\left(x^{2}=9.21\right.$, p value $=0.002456$ ).

The sexes of 33 of the babies born were known; there were 13 males (39.39\%) and 20 females $(60.60 \%)$.

Eight $(62 \%)$ of the males died, while14 $(70 \%)$, of the female babies died.

\section{DISCUSSION}

The perinatal mortality rate found in this study is very high and is similar to the findings of Mutihir and Ujah. ${ }^{3}$ It is worthy of note that Dare et al ${ }^{4}$ reported a much lower rate from lle Ife, Nigeria while much lower rates have been reported from more advanced countries. ${ }^{5-8}$

The role of maternal age and parity in fetal survival following cord prolapse is not certain from this study though there was an observed increase in fetal death with increase in parity. This may probably be because of the population size. Generally however the older woman, ${ }^{7}$ and the multipara, ${ }^{8}$ have been reported to have higher incidences for cord prolapse, and also perinatal mortality, is further reported to be higher among these classess of women. ${ }^{9-12}$ 
The benefits of Antenatal care have been adequately discussed by Donald. ${ }^{13}$ Reproductive performance in the unregistered woman being generally poor; ${ }^{14,15}$ this poor performance was very glaring in this study, where the perinatal mortality rate for the unbooked was almost double that of the booked women. This is similar to the findings of Mutihir and Ujah ${ }^{3}$ and Dare et al. ${ }^{4}$ In this study it was observed that those women that are not booked reported with greater cervical dilatations than the booked women. This probably will translate to delays from time of accident to time of reporting with obvious consequences to the fetus-infant.

There was obvious superiority of abdominal delivery over vaginal in this study with regards to infant survival. The decision about mode of delivery of women with umbilical cord prolapse will depend in part upon whether or not the fetus is alive, the degree of cervical dilatation and also if the fetuses is preterm and the capability of the Neonatal Service of the hospital. Most of the infants delivered abdominally, were alive at admission and the maternal cervices were comparatively less dilated than of those delivered vaginally. It thus appears that the fetuses were likely to have been less degraded metabolically. The long term neurological consequences on the infants were not studied. Many workers have noted increased incidence of cerebral palsy in the infants especially for the very preterm. $^{16}$

The better outcome of normal size babies in this study is not surprising. Most of these fetuses were delivered abdominally and a lesser number of them had died before admission when compared with those that were delivered vaginally. The poorer outcome of babies whose mothers had cervical dilatations of over $7 \mathrm{~cm}$ will not be hard to understand. The more the cervix is dilated the more the time from accident to time of management is likely to be, with consequent greater degree of fetal degradation with many of such fetuses succumbing even before arrival to

\section{References}

1. Exarcu IT. Suferintã Fetalã intra partum. In: Exarcu IT(ed) Reproducerea umana Editura medicala, Bucuresti.1977: 708715.

2. Casey BM, Melatire DD, Leveno K.J. The continuing value of the Apgar score for the assessment of newborn infants. New Engl J Med.2001; 844:467-471.

3. Mutihir J, Ujah IAO - Fetal outcome in umbilical cord prolapse in Jos,Nigeria. Trop J Obstet and Gynaecol.2006; 23(1): 30-33.

4. Dare FO, Owolabi AT, Fasubaa OB, Ezechi OC Umbilical cord prolapse: a clinical study of 69 cases seen at Obafemi Awolowo University Teaching Hospital lle-lfe. East Afr Med J. 1998.75(5): 308-310. hospital. As earlier noted, the less dilated the cervix, the more likely it is that the fetus will be delivered abdominally. Moreover abdominal delivery in the hospital compels the mobilization of all available resources both man and material for the care of the fetus-infant.

The finding that the higher the Apgar score; the better the infant survival was not surprising, it is however disturbing that some of the fetuses that reported alive to the hospital before delivery ended up with zero score.

What is clear from this study is that fetal outcome remains very poor, and survival appears to be influenced by many factors.

Practitioners, both midwifery and medical, should be made constantly aware of this rare obstetric condition, by continuous education processes. There is the need to identify those women at increased risk of their babies having umbilical cord prolapse so that preventive measures can be instituted. When the condition is diagnosed, all available relevant resources should be mobilized.

The practice of electronic fetal monitoring may make for early diagnosis of the condition and appropriate actions taken. Further more a portable real time ultrasound machine in the Birth suite may make the difference when there are doubts about fetal life in the absence of pulsating umbilical cord.

There is the need to develop a protocol for the management of this obstetric emergency, which should from time to time be rehearsed by the respective operators. The need for strengthening the emergency capability of the Birth Unit and also endowing the Neonatal Intensive Care Division with modern equipment, backed-up with appropriate training is likely to improve survival rate of the fetuses- infants.

5. Murphy DJ, MacKenzie IZ. The mortality and morbidity associated with umbilical cord prolapse. $\mathrm{Br} \mathrm{J}$ Obstet Gynaecol.1995; 102:826-830.

6. Uygur D, Kis S, Tuncer R., Ozcan FS, Erkaya S. Risk factors and infant outcomes associated with umbilical cord prolapse. Int J Obstet Gynecol. 2002.78; 127-130.

7. Kahana B, Sheiner E, Levy A, Lazer S, Mazor M. Umbilical cord prolapse and perinatal outcomes. Int $\mathrm{J}$ Gynecol Obstet.2004 Feb; 84(2):127-132.

8. Boyle JJ, Katz VL. Umbilical cord prolapse in current obstetric practice. J Reprod Med. 2005; 50(5): 303-306.

9. Savage EE, Khol SG, Wynn RH. Prolapse of the umbilical cord. Obstet Gynecol.1970:36(4):502-509. 
10. Walreven G, van Roossmalen J. Umbilical Cord Prolapse in Rural Africa. Lancet.1996.16:347(9003):773

11. Harger EO 111, Smythe SR 11. Pregnancy in women over 40. Obstet Gynecol. 1977; 49: 257.

12. Naeye RL. Maternal age, obstetric complications and the outcome of pregnancy. Obstet Gynecol.1980;61:210.

13. Donald I. The Scope of Antenatal Care. In: lan Donald(ed) Practical Obstetric Problems $5^{\text {th }}$ edition, London Lloyd- Luke (Medical Books) Ltd. 1979:1-28.
14. Omene JA, Diejomaoh MFE. Factors influencing perinatal mortality in a Nigerian community. East African Med J .1977; $54: 202$.

15. Ekwempu CC. The influence of Antenatal Care on pregnancy outcome. Trop J Obstet Gynaecol Special edition. 1988; 1(1):67-71.

16. Behrman R. Preventing low birth weight: a pediatric perspective. J Pediatr 1985:197:842. 